\title{
Management of pelvic abscess complicating a rectoanal fistula using endoscopic ultrasound-guided drainage with an electrocautery-enhanced lumen-apposing metal stent
}

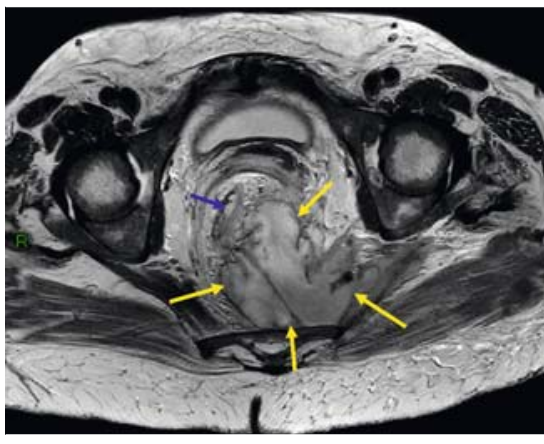

- Fig. 1 View of a large pelvic abscess on magnetic resonance imaging (blue arrow: rectal lumen; orange arrows: pelvic abscess).

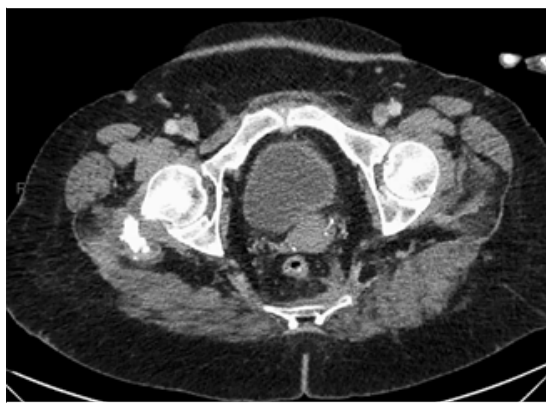

- Fig. 3 Computed tomography 6 months later showed no recurrence of the abscess.

The management of pelvic abscess is mainly radiological or surgical [1]. The use of electrocautery-enhanced lumenapposing metal stents (LAMS) allows efficient drainage of intra-abdominal collections [2]. A few retrospective studies and case series have demonstrated the feasibility and safety of EUS-guided drainage of pelvic abscesses [3-5]. We present a case of a large pelvic abscess complicating a rectoanal fistula that was successfully drained without recurrence using an electrocautery-enhanced LAMS.

During the lockdown due to COVID-19, an 81-year-old woman waited 1 month before attending the emergency room for rectoanal pain with fever. On her admission, computed tomography and
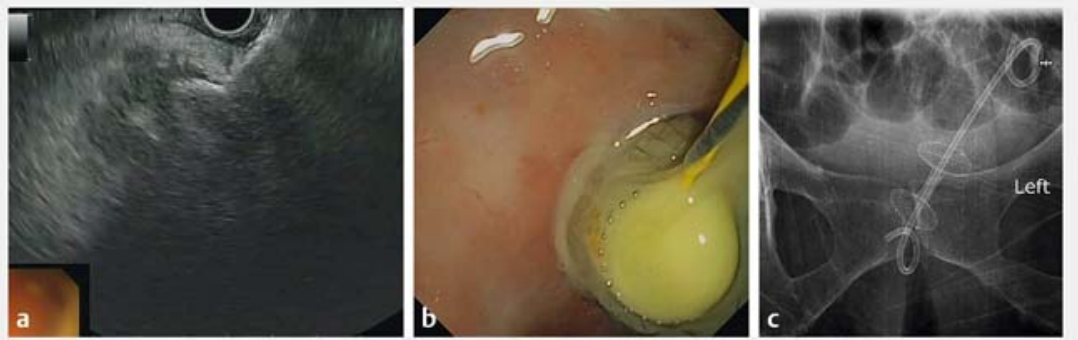

- Fig. 2 Endoscopic ultrasound-guided drainage of a pelvic abscess using an electrocauteryenhanced lumen-apposing metal stent (LAMS). a Deployment of the proximal flange of the LAMS into the pelvic abscess under EUS guidance. $\mathbf{b}$ Deployment of the distal flange of the LAMS into the rectal lumen under endoscopic guidance. $\mathbf{c}$ A double pigtail stent was inserted through the LAMS.
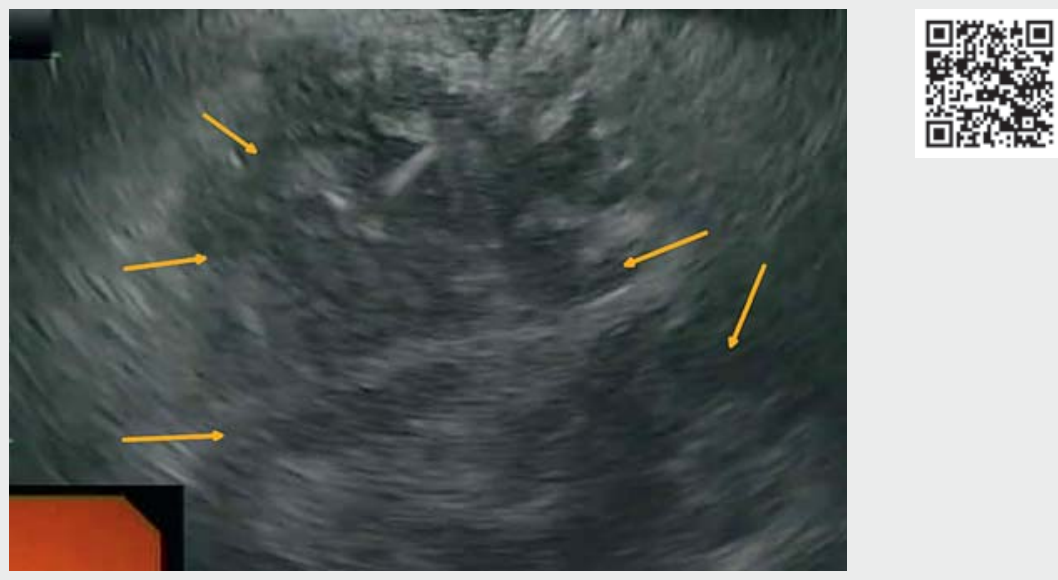

$\nabla$ Video 1 Endoscopic management of a pelvic abscess due to rectoanal fistula (orange arrows: pelvic abscess).

magnetic resonance imaging showed a large pelvic abscess measuring $11 \mathrm{~cm}$ ( $>$ Fig. 1). The location of the pelvic abscess did not allow for radiological drainage, and the patient's medical history precluded surgical management. EUSguided drainage of the pelvic abscess was performed a week after the patient's admission ( $\triangleright$ Video 1 ).

The abscess was accessed using a 19-G needle and aspirated purulent liquid was sent for bacteriological analysis. A 0.025- inch guidewire was introduced through the needle into the abscess. The fistula tract was created using the electrocautery-enhanced LAMS $(10 \times 10 \mathrm{~mm})$. Then, the LAMS was deployed to drain the abscess into the lumen of the colon ( $\triangleright$ Fig. $\mathbf{2 a , b}$ ). During the same procedure, a double pigtail stent was inserted through the LAMS ( $\triangleright$ Fig. $\mathbf{2} \mathbf{c}$ ). No adverse events were reported. At 1 week, endoscopic cleaning of the abscess was performed through the LAMS. The LAMS was re- 
moved after 3 weeks and replaced by a double pigtail stent. At 6 months, the double pigtail stent had migrated outwards and the abscess disappeared without recurrence ( $>$ Fig. $\mathbf{3}$ ).

This case highlights the use of a LAMS in the drainage of a pelvic abscess and successful outcome without recurrence. Future prospective studies are needed to confirm the use of LAMS for this indication and to determine the place of EUS-guided drainage of pelvic collections.

Endoscopy_UCTN_Code_TTT_1AQ_2AF

\section{Competing interests}

The authors declare that they have no conflict of interest.

The authors

Laurent Monino ${ }^{\circledR}$, Hubert Piessevaux, MarieArmelle Denis, Tom G. Moreels

Department of Gastroenterology and Hepatology, Université Catholique de Louvain, Cliniques Universitaires Saint-Luc, Brussels, Belgium

\section{Corresponding author}

\section{Laurent Monino, MD}

Department of Gastroenterology and Hepatology, Cliniques Universitaires Saint Luc, Université Catholique de Louvain, Ave Hippocrate, 10, 1200 Brussels, Belgium laurent.monino@uclouvain.be monino.laurent@hotmail.fr

\section{References}

[1] Sartelli M, Chichom-Mefire A, Labricciosa FM et al. The management of intra-abdominal infections from a global perspective: 2017 WSES guidelines for management of intraabdominal infections. World J Emerg Surg 2017; 12: 29

[2] Sharma P, McCarty TR, Chhoda A et al. Alternative uses of lumen apposing metal stents. World J Gastroenterol 2020; 26: 2715-2728

[3] Fernandez-Urien I. Endoscopic ultrasoundguided drainage of pelvic collections and abscesses. World I Gastrointest Endosc 2010; 2: 223

[4] Lisotti A, Cominardi A, Bacchilega I et al. EUS-guided transrectal drainage of pelvic fluid collections using electrocautery-enhanced lumen-apposing metal stents: a case series. VideoGIE 2020; 5: 380-385

[5] Poincloux L, Caillol F, Allimant C et al. Longterm outcome of endoscopic ultrasoundguided pelvic abscess drainage: a two-center series. Endoscopy 2017; 49: 484-490
Bibliography

Endoscopy 2021; 53: E409-E410

DOI 10.1055/a-1333-0653

ISSN 0013-726X

published online 14.1.2021

(c) 2021. Thieme. All rights reserved.

Georg Thieme Verlag KG, Rüdigerstraße 14, 70469 Stuttgart, Germany

\section{ENDOSCOPY E-VIDEOS}

https:/|eref.thieme.de/e-videos

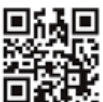

Endoscopy E-Videos is a free access online section, reporting on interesting cases and new

techniques in gastroenterological endoscopy. All papers include a high quality video and all contributions are freely accessible online.

This section has its own submission website at https://mc.manuscriptcentral.com/e-videos 